\title{
Procoagulant state after raloxifene therapy in postmenopausal women
}

\author{
George Dantas Azevedo, M.D., Ph.D. ${ }^{\mathrm{a}, \mathrm{b}}$ Rendrik França Franco, M.D., Ph.D., ${ }^{\mathrm{c}}$ \\ Márcia Sueli Baggio, M.Sc., ${ }^{\mathrm{a}}$ Técia Maria de Oliveira Maranhão, M.D., Ph.D., ${ }^{\mathrm{b}}$ \\ and Marcos Felipe Silva de Sá, M.D., Ph.D. ${ }^{\mathrm{a}}$
}

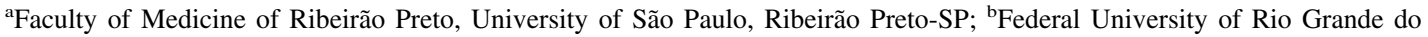
Norte, Natal-RN; and ${ }^{\mathrm{C} H e m o s t a s i s ~ L a b o r a t o r y, ~ F l e u r y ~ R e s e a r c h ~ I n s t i t u t e, ~ S a ̃ o ~ P a u l o-S P, ~ B r a z i l ~}$

\begin{abstract}
Objective: To investigate the effects of raloxifene on the hemostatic system in postmenopausal women.
Design: A prospective longitudinal study.

Setting: Outpatient clinic of the Faculty of Medicine of Ribeirão Preto, Brazil.

Patient(s): Sixteen postmenopausal women aged $56.8 \pm 5.9$ years (mean \pm SD).

Intervention(s): Raloxifene hydrochloride (60 mg once daily) was administered orally for a period of 6 months. Main Outcome Measure(s): Plasma activities of coagulation factors (II, V, VII, VIII, IX, X, XI, XII, and fibrinogen), prothrombin-derived fragment $1+2$, and activated protein C (APC) sensitivity ratio were measured at baseline and after 1,3, and 6 months of treatment.

Result(s): Factor VIII activity increased by $17.1 \%$ and $26.9 \%$ at 3 and 6 months of treatment, respectively, compared with baseline. Factor XI and FXII activities significantly increased by $10.9 \%$ and $43.1 \%$, respectively, after 6 months compared with baseline. A significant reduction of APC sensitivity ratio also was observed after 6 months of treatment.

Conclusion(s): A procoagulant state characterized by increased factor VIII, XI, and XII plasma levels and by reduced APC sensitivity was observed after raloxifene therapy in post-menopausal women. (Fertil Steril ${ }^{\circledR} 2005$; 84:1680-4. (2005 by American Society for Reproductive Medicine.)
\end{abstract}

Key Words: Climacteric, hemostatic system, raloxifene, SERMs

Raloxifene is a selective estrogen receptor modulator and exerts tissue-selective effects similar to those of estrogen (E) on bone and serum lipids, without any apparent stimulatory effect on mammary and uterine tissues (1-5). The effect of raloxifene on the cardiovascular system in postmenopausal women has been studied, and the favorable results have been explained mainly by its effects on metabolic changes in lipoproteins, homocysteine, and improved endothelium-dependent vasomotricity, preventing arteriosclerosis and acting as a vasodilating agent (6-9).

Despite these benefits, raloxifene therapy increases the risk of venous thromboembolism (VTE) by approximately threefold, a similar effect to that observed with hormone therapy (HT) (4). Although a large body of data supports a procoagulant state related to $\mathrm{E}$ administration, there are few published data on the effect of raloxifene on hemostatic parameters in postmenopausal women. In an article published elsewhere (10), we reported that raloxifene therapy is associated with a significant reduction in plasma antithrom-

Received January 12, 2005; revised and accepted June 5, 2005.

Supported by Faculty of Medicine of Ribeirão Preto, University of São Paulo, Ribeirão Preto-SP, Brazil.

Presented at the 10th World Congress on Menopause, Berlin, Germany, June 10-14, 2002.

Reprint requests: George Dantas Azevedo, M.D., Departamento de Morfologia do Centro de Biociěncias, Campus Universitário, BR 101, Lagoa Nova, Natal-RN, Brazil 59078-970 (FAX: +55-084-2153431; E-mail: georgedantas@uol.com.br). bin activity, suggesting that this effect may contribute to a procoagulant state and partly explain the increased risk of VTE in raloxifene users. Here, we report the results of a longitudinal study assessing the effects of raloxifene on other hemostatic parameters in healthy postmenopausal women.

\section{MATERIALS AND METHODS Study Subjects}

Sixteen postmenopausal women were enrolled in a prospective longitudinal study. General characteristics of the subjects were as follows (values given as mean \pm SD): age, 56.8 \pm 5.9 years; duration of menopause, $9.3 \pm 5.5$ years; and body mass index, $25.8 \pm 3.7 \mathrm{~kg} / \mathrm{m}^{2}$. Postmenopausal status was defined as cessation of menses for $\geq 1$ year, with estradiol $\left(\mathrm{E}_{2}\right)$ concentrations of $<20 \mathrm{pg} / \mathrm{mL}$ and follicle-stimulating hormone (FSH) concentrations of $\geq 30 \mathrm{mIU} / \mathrm{mL}$.

Women were ineligible if they had a history of thromboembolic disorders or of hepatic, renal, endocrinological, gastrointestinal, or cardiovascular disease. Other exclusion criteria were as follows: substantial postmenopausal symptoms; abnormal uterine bleeding; a history of uterine, breast, or ovarian cancer; or clinically relevant abnormalities in laboratory tests of hematological, renal, and hepatic function. None of the participants was a smoker or an illicit drug user or was taking any medication that might interfere with laboratory evaluation of the hemostatic system. Subjects 
could not have taken conjugated $\mathrm{E}$ or another hormone replacement regimen within the previous 3 months.

All participants were given information about the trial, and written informed consent was obtained before enrollment. The protocol was approved by the institutional review board.

\section{Study Design}

Participants received oral raloxifene hydrochloride $(60 \mathrm{mg}$ once per day; Eli Lilly and Company, Indianapolis, IN) during a period of 6 months for prevention and treatment of osteoporosis. Hemostatic parameters were measured in all users at baseline and after 1, 3, and 6 months of treatment. Other clinical and laboratory parameters considered during the treatment period were as follows: weight, body mass index, waist-hip ratio, systolic and diastolic blood pressures, heart rate, blood cell count, and laboratory parameters of hepatic and renal function.

Fasting venous blood samples were collected between 8 $\mathrm{AM}$ and $10 \mathrm{AM}$. Before blood collection, the participants rested in the sitting position for at least 10 minutes. Blood samples were collected atraumatically from the antecubital vein with a $21 \mathrm{G}$ butterfly infusion set and were placed in plastic tubes containing an anticoagulant solution $(9 \mathrm{~mL}$ whole blood to $1 \mathrm{~mL}$ of $3.2 \%$ sodium citrate). The blood samples were immediately transported to the hemostasis laboratory, platelet-poor plasma was obtained by centrifugation at $10^{\circ} \mathrm{C}$ for 20 minutes at $1,500 \mathrm{~g}$, and plasma samples were stored at $-80^{\circ} \mathrm{C}$ until analysis.

Complete hematological counts and global clotting tests, including prothrombin time, thrombin time, and activated partial thromboplastin time, were performed in all samples. Recommendations of approved guidelines of the National Committee for Clinical Laboratory Standards for collection, transport, and processing of blood specimens for coagulation testing were followed strictly (11).

\section{Laboratory Assays}

To estimate possible effects on the hemostatic system, plasma activities of coagulation factors (II, V, VII, VIII, IX, $\mathrm{X}, \mathrm{XI}, \mathrm{XII}$, and fibrinogen), prothrombin-derived fragment $1+2(\mathrm{~F} 1+2)$, and the normalized activated protein $\mathrm{C}(\mathrm{APC})$ sensitivity ratio (nAPCsr) were measured at baseline and after 1,3 , and 6 months of treatment.

Factor assays were performed on an MLA Electra 1600 analyzer (Automatic Coagulation Analyzer; Medical Laboratory Automation, Inc., Pleasantville, NY) by using factordeficient substrates (Helena Laboratories, Inc, Beaumont, TX), and nAPCsr was measured by using a commercial activated partial thromboplastin time-based assay, the TEClot aPC Sensitivity (TECO Medical Instruments, Neufahrn, Germany). The quantitative determination of $\mathrm{F} 1+2$ was performed by using a sensitive enzyme immunoassay kit, the Enzygnost F1+2 (Dade Behring, Inc, Deerfield, IL).

\section{Statistical Analysis}

The normality of distribution of variables was tested by using the Kolmogorov-Smirnov test. The results were expressed as mean $\pm \mathrm{SD}$ at different periods, and the adjusted mean changes from baseline with two-sided $95 \%$ confidence intervals were estimated and statistically tested by Student's paired $t$ test. Statistical significance was defined as $P<.05$.

\section{RESULTS Clinical and Laboratory Follow-Up}

We observed no clinically evident thromboembolic events during the study. Significant increases in mean body weight $(+0.65 \mathrm{~kg})$ and body mass index $\left(+0.27 \mathrm{~kg} / \mathrm{m}^{2}\right)$ were observed after 6 months of therapy, compared with baseline $(P<.05)$. No significant changes were observed in waist-tohip ratio, heart rate, or blood pressure during the study. No significant differences were observed either in biochemical parameters such as fasting glycemia, creatinine, urea, total bilirubin, $\gamma$-glutamyl-transferase, alanine aminotransferase, aspartate aminotransferase, and C-reactive protein.

Mean hemoglobin (grams per deciliter) and hematocrit (percentage) levels, for pretreatment assessment, were 13.4 \pm 1.0 and $39.4 \pm 2.94$, respectively, without significant modifications during the study period. Similarly, no changes were verified in leukocyte and platelet counts, with baseline values of $5.5 \pm 1.62\left(\times 10^{3}\right.$ per microliter $)$ and $225.6 \pm 34.17$ $\left(\times 10^{3}\right.$ per microliter), respectively.

\section{Hemostatic Factors}

No significant alterations were observed in coagulation screening tests (activated partial thromboplastin time, prothrombin time, and thrombin time; data not shown). However, when evaluating plasma activities of coagulation factors, we observed significant modifications for factors VIII, $\mathrm{XI}$, and XII after raloxifene administration.

A gradual increase in plasma factor VIII level was observed, and this effect was significant at 3 and 6 months compared with baseline $(+17.1$ and $+26.9 \%$, respectively; $P<.05)$. Also, an increase in plasma factor XI level after 6 months, compared with baseline $(+10.9 \% ; P<.05)$, was observed. A marked increase in activity was observed in relation to factor XII after 1, 3, and 6 months of raloxifene therapy, compared with baseline $(+34.6 \%,+49.5 \%$, and $+43.1 \%$, respectively; $P<.05$ ). The mean values of plasma fibrinogen levels, F1+2 concentrations, and activities of other coagulation factors were unchanged among study periods (Table 1).

We also observed that nAPCsr reduced significantly from $3.1 \pm 0.4$ (baseline) to $2.8 \pm 0.4(P<.05)$ after 6 months of therapy with raloxifene. 


\section{TABLE 1}

\section{Comparison of parameters across study periods.}

\begin{tabular}{|c|c|c|c|c|}
\hline Parameter & Baseline & $1 \mathrm{mo}$ & $3 \mathrm{mo}$ & $6 \mathrm{mo}$ \\
\hline $\begin{array}{l}\text { Fibrinogen } \\
\text { Mean } \pm \mathrm{SD} \\
\text { Change from baseline }\end{array}$ & $289.9 \pm 43.8$ & $\begin{array}{c}271.9 \pm 52.1 \\
-18.1(-45.7,9.6)\end{array}$ & $\begin{array}{c}281.1 \pm 51.6 \\
-8.8(-44.7,27.1)\end{array}$ & $\begin{array}{c}309.1 \pm 48.4 \\
19.1(-8.3,46.6)\end{array}$ \\
\hline $\begin{array}{l}\text { Factor II } \\
\text { Mean } \pm \text { SD } \\
\text { Change from baseline } \\
\text { Factor } V\end{array}$ & $100.6 \pm 12.9$ & $\begin{array}{r}99.9 \pm 13.5 \\
-0.8(-5.8,4.3)\end{array}$ & $\begin{array}{r}101.2 \pm 15.1 \\
0.6(-3.5,4.8)\end{array}$ & $\begin{array}{c}100.2 \pm 13.9 \\
-0.4(-5.0,4.1)\end{array}$ \\
\hline $\begin{array}{l}\text { Mean } \pm \mathrm{SD} \\
\text { Change from baseline }\end{array}$ & $129.6 \pm 18.6$ & $\begin{array}{r}127.9 \pm 15.3 \\
-1.8(-9.2,5.7)\end{array}$ & $\begin{array}{r}133.9 \pm 19.0 \\
4.2(-1.3,9.8)\end{array}$ & $\begin{array}{l}132.3 \pm 16.5 \\
2.7(-1.9,7.3)\end{array}$ \\
\hline Change from baseline & $118.1 \pm 21.1$ & $\begin{array}{c}110.1 \pm 18.3^{\mathrm{a}} \\
-8.1(-13.8,-2.4)\end{array}$ & $\begin{array}{r}115.6 \pm 21.8 \\
-2.6(-9.2,4.1)\end{array}$ & $\begin{array}{c}116.4 \pm 25.6 \\
-1.7(-6.0,2.5)\end{array}$ \\
\hline $\begin{array}{l}\text { Factor VIII } \\
\text { Mean } \pm \text { SD } \\
\text { Change from baseline }\end{array}$ & $90.1 \pm 32.4$ & $\begin{array}{c}99.4 \pm 32.5 \\
9.2(-1.7,20.2)\end{array}$ & $\begin{array}{r}107.2 \pm 33.9^{a} \\
17.1(3.1,31.0)\end{array}$ & $\begin{array}{c}117.1 \pm 36.6^{\mathrm{a}} \\
26.9(8.3,45.6)\end{array}$ \\
\hline $\begin{array}{l}\text { Factor IX } \\
\quad \text { Mean } \pm \text { SD } \\
\text { Change from baseline } \\
\text { Factor } X\end{array}$ & $77.3 \pm 19.6$ & $\begin{array}{c}80.2 \pm 17.6 \\
2.9(-4.2,10.0)\end{array}$ & $\begin{array}{c}78.1 \pm 13.7 \\
0.8(-8.4,10.0)\end{array}$ & $\begin{array}{c}78.5 \pm 17.2 \\
1.2(-5.5,7.8)\end{array}$ \\
\hline $\begin{array}{l}\text { Mean } \pm \mathrm{SD} \\
\text { Change from baseline }\end{array}$ & $106.9 \pm 13.2$ & $\begin{array}{l}107.3 \pm 15.0 \\
0.4(-3.6,4.4)\end{array}$ & $\begin{array}{r}108.8 \pm 18.8 \\
1.9(-2.5,6.4)\end{array}$ & $\begin{array}{l}109.4 \pm 19.1 \\
2.5(-2.0,7.0)\end{array}$ \\
\hline $\begin{array}{l}\text { Mean } \pm S D \\
\text { Change from baseline }\end{array}$ & $96.4 \pm 24.0$ & $\begin{array}{c}104.5 \pm 37.5 \\
8.1(-13.1,29.2)\end{array}$ & $\begin{array}{c}98.9 \pm 29.3 \\
2.4(-9.2,14.1)\end{array}$ & $\begin{array}{c}107.4 \pm 24.9^{a} \\
10.9(0.5,21.4)\end{array}$ \\
\hline $\begin{array}{l}\text { Factor XII } \\
\text { Mean } \pm \mathrm{SD} \\
\text { Change from baseline }\end{array}$ & $147.8 \pm 53.7$ & $\begin{array}{r}182.4 \pm 63.0^{a} \\
34.6(10.5,58.8)\end{array}$ & $\begin{array}{r}197.3 \pm 55.6^{a} \\
49.5(25.5,73.5)\end{array}$ & $\begin{array}{r}190.9 \pm 60.3^{a} \\
43.1(13.5,72.6)\end{array}$ \\
\hline $\begin{array}{l}\mathrm{F} 1+2 \\
\quad \text { Mean } \pm \mathrm{SD} \\
\text { Change from baseline }\end{array}$ & $0.8 \pm 0.2$ & $\begin{array}{c}0.8 \pm 0.2 \\
0.0(-0.1,0.1)\end{array}$ & $\begin{array}{c}0.8 \pm 0.2 \\
0.0(-0.1,0.1)\end{array}$ & $\begin{array}{c}0.8 \pm 0.3 \\
0.0(-0.1,0.1)\end{array}$ \\
\hline \multicolumn{5}{|c|}{$\begin{array}{l}\text { Note: Values are expressed as mean } \pm \text { SD at different periods and adjusted mean changes from baseline }(95 \% \text { confidence } \\
\text { intervals). } \\
\text { a } P<.05 \text { compared with baseline, Student's } t \text { test. }\end{array}$} \\
\hline
\end{tabular}

\section{DISCUSSION}

Raloxifene increases the risk of VTE similarly to what has been observed with tamoxifen and $\mathrm{E}$ use in postmenopausal women (4, 12-14). In the Multiple Outcomes of Raloxifene Evaluation (MORE) trial, the risk of venous thromboembolic disease (deep venous thrombosis or pulmonary embolism) was found to be 3.1 times higher (95\% confidence interval, 1.5 to 6.2 ) in women assigned to the raloxifene group than to the placebo group. These findings led those investigators to recommend that women with a history of VTE should not take raloxifene and that women currently taking this medication should discontinue it before major surgery or during periods of immobilization (4).

The reasons that a woman on raloxifene therapy is at a higher risk of VTE are not well understood. Hemostatic effects of raloxifene on hemostasis have been explored only partially, and the information available comes from clinical trials attempting to assess isolated points of the hemostatic system. Walsh et al. (9) performed a multicentric study comparing raloxifene, HRT, and placebo and assessing fibrinogen, plasminogen activator inhibitor- $1, \mathrm{~F} 1+2$, and fibrinopeptide A levels. In that study, the investigators observed a significant reduction in fibrinogen levels of $10 \%$ to $12 \%$ among raloxifene users, an effect not observed in the HRT group. No significant alterations associated to raloxifene were detected in $\mathrm{F} 1+2$, fibrinopeptide $\mathrm{A}$, and plasminogen activator inhibitor-1 levels. In another study involving more extensive assessment of the hemostatic system, De Valk-de Roo et al. (15) also observed a fibrinogen reduction associated with raloxifene use but without significant alter- 
ations in other coagulation parameters assessed. In relation to fibrinolysis assessment, no significant modifications were detected in any of the parameters considered, in groups which received raloxifene. Conversely, estrogen (E) replacement caused plasminogen activator inhibitor-1 reduction (a beneficial effect) but a transitory increase in $\mathrm{F} 1+2$, suggesting a greater thrombin generation and activation of coagulation in this treatment group.

The present study was designed specifically to determine the effects of raloxifene on the hemostatic system by using extensive assessment methodology and rigorous sample selection criteria to include healthy postmenopausal women, without additional risk factors for arterial or venous thrombosis. In our study, we observed statistically significant increases in the procoagulant activity levels of factors VIII, XI, and XII after raloxifene use. The increase in factor VIII activity particularly is important in relation to VTE risk, because a significant association has been reported between high factor VIII levels and a greater predisposition to thromboembolic disease. The associated relative risk with high factor VIII levels is around 4.8, and it is estimated that for each $10-\mathrm{IU} / \mathrm{dL}$ (or $10 \%$ of coagulant activity) increment, the risk for a single episode of VTE increases by $10 \%$, and that for recurrent disease, by $24 \%$ (16-18).

By analyzing the interaction of venous thrombosis risk factors in oral hormonal contraceptive users, Bloemenkamp et al. (19) reported a 3.8- to 4-fold risk increase associated with the isolated presence of high factor VIII levels or prior contraceptive use. However, after analyzing the effect of the association of these two risk factors on VTE occurrence, those investigators verified a 10 -fold risk increase. This evidence suggests that the $26.9 \%$ increase in factor VIII procoagulant activity observed in our study may represent a plausible pathophysiological mechanism by which raloxifene therapy contributes to VTE occurrence in postmenopausal women.

In relation to the other coagulation factors, we observed that raloxifene treatment caused significant increases in factor XI and XII activity levels. Coagulation factor XI contributes to thrombin generation and is involved in both fibrin formation and protection against fibrinolysis $(20,21)$, and the increase in its coagulant activity level also has been associated with increased VTE risk (22). Thus, it is possible that the increase in factor XI plasma levels associated with raloxifene use that is described in this study also may contribute to VTE risk in users of this medication.

We verified a $34.6 \%$ increase in factor XII activity at 1 month and an even greater increment at 3 and 6 months (49.5\% and $43.1 \%$, respectively). However, the contribution of this significant and progressive increase of coagulation factor XII level for VTE risk after raloxifene use is not clear because there is no scientific evidence indicating a significant association between factor XII level increase and VTE occurrence. Thus, the clinical relevance or the pathophysiological consequence of this finding is not possible to establish in light of current scientific knowledge.

Resistance to the anticoagulant action of APC is a highly prevalent risk factor for venous thrombosis among individuals of Caucasian origin (23). In most cases, APC resistance is associated with a single missense mutation in the gene for coagulation factor $\mathrm{V}$, designated factor $V$ Leiden. However, a poor APC response also may result from several acquired conditions, some of which clearly are involved in the pathogenesis of venous thrombosis, such as inflammatory diseases, pregnancy, hormonal contraceptive use, and elevated levels of fibrinogen and factor VIII $(23,24)$. Data indicate that acquired reduction in sensitivity to APC is associated with a 2.5- to 4-fold VTE risk increase and that the combination of the risk factors of HRT use and APC resistance is associated with an approximately 13-fold increase in VTE risk in women $(25,26)$.

In our study, we reported that raloxifene use is associated with a reduction in sensitivity to APC, suggesting that this mechanism also could be involved in the increased thrombotic risk related to raloxifene therapy in postmenopausal women. These results are not in agreement with those of a recent report that raloxifene had no significant effect on nAPCsr compared with placebo in both women and men (27), and the reasons for these contrasting findings remain to be explained.

Some investigators have shown that the presence of elevated factor VIII levels is associated with lowered nAPCsr, even in the absence of factor V Leiden (28-30). The pathophysiological mechanism of this association can be understood by considering the physiological role of protein $\mathrm{C}$, because its anticoagulant activity is through the cleavage and inactivation of factors Va and VIIIa, in such a way that the occurrence of a significant increase in factor VIII levels may lead to a state of APC resistance.

The results of this prospective study show for the first time that raloxifene use is associated with significant increases in plasma factors VIII, XI, and XII levels and with an acquired APC resistance state, all of which, except factor XII, are well-established risk factors for VTE. Additionally, in an article published elsewhere, we found that raloxifene administration significantly decreased plasma antithrombin activity at 3 months $(-5.1 \%)$ and 6 months $(-6.5 \%)$ of treatment, suggesting that this effect also may contribute to a procoagulant state and partly explain the increased risk of VTE in raloxifene users. Compared with baseline, raloxifene did not significantly affect protein C activity or protein S level (10). Taken together, the results suggest that these effects may lead to a procoagulant state, conceivably contributing to the increased VTE risk that is observed in postmenopausal women treated with raloxifene. 


\section{REFERENCES}

1. Brzozowski AM, Pike ACW, Dauter Z, Hubbard RE, Bon T, Engström $\mathrm{O}$, et al. Molecular basis of agonism and antagonism in the oestrogen receptor. Nature 1997;389:753-7.

2. Delmas PD, Bjarnason NH, Mitlak BH, Ravoux A-C, Shah AS, Huster WJ, et al. Effects of raloxifene on bone mineral density, serum cholesterol concentrations, and uterine endometrium in postmenopausal women. N Engl J Med 1997;337:1641-7.

3. Ettinger B, Black DM, Mitlak BH, Knickerbocker RK, Nickelsen T, Genant HK, et al. Reduction of vertebral fracture risk in postmenopausal women with osteoporosis treated with raloxifene: results from a 3-year randomized clinical trial. Multiple Outcomes of Raloxifene Evaluation (MORE) Investigators. JAMA 1999;282:637-45.

4. Cummings SR, Eckert S, Krueger KA, Grady D, Powles TJ, Cauley JA, et al. The effect of raloxifene on risk of breast cancer in postmenopausal women: results from the MORE randomized trial. Multiple Outcomes of Raloxifene Evaluation. JAMA 1999;281:2189-97.

5. Azevedo GD, do Prado MF, Ferriani RA, dos Reis RM, Berezowski AT, Ribeiro TF, et al. Raloxifene therapy does not affect uterine blood flow in postmenopausal women: a transvaginal Doppler study. Maturitas 2004;47:195-200.

6. Saitta A, Morabito N, Frisina N, Cucinotte D, Corrado F, D' anna R, et al. Cardiovascular effects of raloxifene hydrochloride. Cardiovasc Drug Rev 2001;19:57-74.

7. Bush TL, Blumenthal R, Lobo R, Clarkson TB. SERMs and cardiovascular disease in women. How do these agents affect risk? Postgrad Med 2001;Spec No:17-24.

8. Herrington DM, Klein KP. Effects of SERMs on important indicators of cardiovascular health: lipoproteins, hemostatic factors, and endothelial function. Womens Health Issues 2001;11:95-102.

9. Walsh BW, Kuller LH, Wild RA, Paul S, Farmer M, Lawrence JB, et al. Effects of raloxifene on serum lipids and coagulation factors in healthy postmenopausal women. JAMA 1998;279:1445-51.

10. Azevedo GD, Franco RF, Baggio MS, Maranhão TMO, Ferriani RA, Silva-de-Sá MF. Effects of raloxifene therapy on the anticoagulant system in postmenopausal women. Climacteric 2003;6:140-5.

11. National Committe for Clinical Laboratory Standards (NCCLS). Collection, transport, and processing of blood specimens for testing plasma-based coagulation assays; approved guideline, fourth edition. NCCLS document H21-A4, vol. 23, no. 35, 2003.

12. Grady D, Ettinger B, Moscarelli E, Plouffe L Jr, Sarkar S, Ciaccia A, et al, and the Multiple Outcomes of Raloxifene Evaluation Investigators. Safety and adverse effects associated with raloxifene: multiple outcomes of raloxifene evaluation. Obstet Gynecol 2004;104:837-44.

13. Daly E, Vessey MP, Hawkins MM, Carson JL, Gough P, Marsh S. Risk of venous thromboembolism in users of hormone replacement therapy. Lancet 1996;348:977-80.

14. Deitcher SR, Gomes MP. The risk of venous thromboembolic disease associated with adjuvant hormone therapy for breast carcinoma: a systematic review. Cancer 2004;101:439-49.
15. De Valk-de Roo GW, Stehouwer CD, Meijer P, Mijatovic V, Kenemans $\mathrm{P}$, Cohen F, et al. Both raloxifene and estrogen reduce major cardiovascular risk factors in healthy postmenopausal women: a 2-year, placebo-controlled study. Arterioscler Thromb Vasc Biol 1999;19: 2993-3000.

16. Koster T, Blann AD, Briet E, Vanderbroucke JP, Rosendaal FR. Role of clotting factor VIII in effect of von Willebrand factor on occurrence of deep-vein thrombosis. Lancet 1995;345:152-5.

17. Kraaijenhagen RA, In't Anker PS, Koopman MMW, Reitsma PH, Prins $\mathrm{MH}$, van den Ende A, et al. High plasma concentration of factor VIIIc is a major risk factor for venous thromboembolism. Thromb Haemost 2000;83:5-9.

18. Kamphuisen PW, Eikenboom JCJ, Bertina RM. Elevated factor VIII levels and the risk of thrombosis. Arterioscler Thromb Vasc Biol 2001;21:731-8.

19. Bloemenkamp KW, Helmerhorst FM, Rosendaal FR, Vandenbroucke JP. Venous thrombosis, oral contraceptives and high factor VIII levels. Thromb Haemost 1999;82:1024-7.

20. Dahlback B. Blood coagulation. Lancet 2000;355:1627-32.

21. Butenas S, Mann KG. Blood coagulation. Biochemistry 2002;67:3-12.

22. Meijers JCM, Tekelenburg WLH, Bouma BN, Bertina RM, Rosendaal FR. High levels of coagulation factor XI as a risk factor for venous thrombosis. N Engl J Med 2000;342:696-701.

23. Spannagl M, Dick A, Assmann A, Heinemann L, Schramm W. Resistance to activated protein $\mathrm{C}$ in women using oral contraceptives. Semin Thromb Hemost 1998;24:423-30.

24. Franco RF, Reitsma PH. Genetic risk factors of venous thrombosis. Hum Genet 2001;109:369-84.

25. De Visser MC, Rosendaal FR, Bertina RM. A reduced sensitivity for activated protein $\mathrm{C}$ in the absence of factor $\mathrm{V}$ Leiden increases the risk of venous thrombosis. Blood 1999;93:1271-6.

26. Lowe G, Woodward M, Vessey M, Rumley A, Gough P, Daly E. Thrombotic variables and risk of idiopathic venous thromboembolism in women aged 45-64 years. Relationships to hormone replacement therapy. Thromb Haemost 2000;83:530-5.

27. Duschek EJ, Neele SJ, Thomassen MC, Rosing J, Netelenbos C. Effect of raloxifene on activated protein $\mathrm{C}$ (APC) resistance in postmenopausal women and on APC resistance and homocysteine levels in elderly men: two randomized placebo-controlled studies. Blood Coagul Fibrinolysis 2004;15:649-55.

28. Henkens CM, Bom VJ, van der Meer J. Lowered APC-sensitivity ratio related to increased factor VIII-clotting activity. Thromb Haemost 1995;74:1198-9.

29. Laffan MA, Manning R. The influence of factor VIII on measurement of activated protein C resistance. Blood Coagul Fibrinolysis 1996;7: 761-5.

30. Kamphuisen PW, Eikenboom JC, Bertina RM. Elevated factor VIII levels and the risk of thrombosis. Arterioscler Thromb Vasc Biol 2001;21:731-8. 